\title{
Krytyczne retro \\ a kształtowanie pamięci zbiorowej \\ w kinie amerykańskim XXI wieku
}

\section{Critical Retro and Collective Memory in the American Cinema of the 21st Century}

Abstract: Among others, retromania means bringing back the past eras and constructing the memory of them in contemporary popculture. The critical retro is considered here as a set of cinematic devices used in order to manage collective memory and create a certain imagery of the relatively recent past. The critical retro of the 21st century American cinema "aesthetically colonizes" the past, yet in doing so, it does not reflect any nostalgic vision of collective memory. Movies analysed in the article are characteristic for their careful use of the retro fashion and their employment of such devices as extreme or excessive stylization, particular narration, and familiar narrative patterns (family melodrama) in order to influence collective memory of the past. At the same time, what they offer in terms of the story, character, and the perception of the depicted era, is highly subversive because they openly address issues that were either omitted or ignored in the previous years for a number of reasons.

Keywords: retro, nostalgia, nostalgia film, critical retro, memory studies, collective memory

Truizmem jest stwierdzenie, że przeszłość dostarczała inspiracji i tematów dla kina już od najwcześniejszych etapów jego istnienia. Tak - co oczywiste - pozostało do dziś, chociaż sam sposób ekranowego problematyzowania historii ulega stałym przemianom. Nigdy też zagadnienie to nie było dla kina tak istotne jak obecnie, gdy właśnie powroty do przeszłości i tematyka pamięci są jedną z najistotniejszych dominant popkultury (nie tylko) amerykańskiej, w tym kinematografii. O ile jednak przed latami sześćdziesiątymi XX wieku i wkroczeniem na wielkie ekrany postmodernizmu historia stanowiła najczęściej albo tło dla perypetii bohaterów, albo metaforę współczesności, o tyle w drugiej połowie XX wieku i w pierwszych dekadach XXI jest już wysuwana na plan pierwszy samoświadomych narracji filmowych - nie tylko jako „dzieje”, lecz także przedmiot narratywizowania i pamiętania. Zabieg ten wpisuje się w szersze trendy kulturowe i społeczne (a jednocześnie wyznacza je bądź wzmacnia), a jednym z nurtów podejmujących tak zarysowane wyzwanie jest krytyczne retro XXI wieku. Przed zdefiniowaniem go i rozpatrzeniem w kategorii kinowej poetyki pamięci warto jednak zarysować 
główne strategie reprezentacji historii we współczesnym kinie amerykańskim. Są to afirmacja przeszłości, podejście krytyczne oraz podejście „neutralne”, oparte przede wszystkim na formalnych strategiach postmodernizmu (przy czym dla definiowania krytycznego retro istotne są przede wszystkim dwie pierwsze).

\section{Powroty do przeszłości}

Przekrojowe spojrzenie na sposoby uobecniania przeszłości w kinie amerykańskim ostatnich paru dekad wskazuje na kilka tendencji, zależnych - najogólniej rzecz ujmując - od mechanizmów upamiętniania i strategii kreowania pamięci zbiorowej determinujących ustosunkowanie się do minionych zdarzeń. Pierwszym podejściem byłaby afirmacja przeszłości przejawiająca się w zjawisku filmu nostalgicznego, opisanego przez Fredrica Jamesona ${ }^{1}$. Zdaniem badacza postmodernizmu, za przykłady wybierającego Amerykańskie graffiti (American Graffiti, 1973, reż. George Lucas) i Gwiezdne wojny (Star Wars. Episode IV: A New Hope, 1977, reż. George Lucas), obejmuje ono zarówno odniesienia do minionych czasów przedstawianych jako kraina mlekiem i miodem płynąca, pozbawiona konfliktów i prezentująca wizję „ ,historii bez winy”, jak też przywołanie konkretnych doświadczeń popkulturowych i kinematograficznych, cofających odbiorców do wspomnień i atmosfery sielskiego dzieciństwa oraz wczesnej młodości. Przykładem podejścia pierwszego jest Amerykańskie graffiti, wpisujące się w grupę filmów idealizujących „hipnotyzującą minioną rzeczywistość ery Eisenhowera”. W drugim wypadku, Gwiezdne wojny - choć oczywiście nie odnoszą się do rzeczywistości istniejącej - przywołują generacyjne doświadczenie popkulturowe pokoleń dorastających w erze Eisenhowera. Awanturniczo-przygodowe programy telewizyjne i kino science fiction są bowiem „zdolne [...] zaspokoić głębsze i prawdziwie nostalgiczne pragnienie powrotu do tamtego okresu i powtórnego przeżycia dawnych, obcych wytworów jego estetyki”"4.

Ponieważ marketing przeszłości jest jedną z wiodących tendencji produkcyjnych dzisiejszego Hollywood, a popyt na nostalgię nadal nie ustaje, tak zarysowane wyznaczniki filmu nostalgicznego spełnia wiele późniejszych produkcji, a nawet całych trendów. Do estetyczno-popkulturowego przeżycia o charakterze

1. Fredric Jameson, Postmodernizm albo kulturowa logika późnego kapitalizmu, przeł. Katarzyna Malita, „Pismo Literacko-Artystyczne”, 1988, nr 4.

2. Svetlana Boym, The Future of Nostalgia, Basic Books, New York 2001, s. XIV.

3. Jameson, Postmodernizm albo..., s. 75.

4. Fredric Jameson, Postmodernizm i społeczeństwo konsumpcyjne, przeł. Przemysław Czapliński, w: Postmodernizm. Antologia przekładów, red. Ryszard Nycz, Wydawnictwo Baran i Suszczyński, Kraków 1998, s. 198. 
intersubiektywnym odwołują się przede wszystkim twórcy operujący nie przeszłością rzeczywistą, ale chęcią ewokowania (i kapitalizowania) medialnie zapośredniczonych wspomnień. Najlepszym przykładem będą remaki filmów wytwórni Disneya, zarówno prawdziwych klasyków (Księga dżungli [Jungle Book, 2016, reż. Jon Favreau], nowa wersja filmu z 1967 roku w reżyserii Wolfganga Reithermana), jak i tych, które stały się wczesnymi doświadczeniami kinowymi dzisiejszych dwudziesto- i trzydziestolatków. Wskazuje na to aktorskie wydanie Pięknej i Bestii (Beauty and the Beast, 2017, reż. Bill Condon), do tego stopnia opierające się na popularności animowanego filmu wytwórni Disneya (Beauty and the Beast 1991, reż. Gary Trousdale, Kirk Wise), że aż odtwarzające go omal dosłownie (te same piosenki, analogiczne ujęcia, kostiumy, gesty wzorowane na animacji). Trwałość tego zjawiska (nowszym przykładem jest remake jednego z największych przebojów lat dziewięćdziesiątych, czyli Króla lwa [The Lion King, 1994, reż. Roger Allers, Rob Minkoff] $]^{5}$, a studio planuje kolejne oraz następną trylogię Gwiezdnych wojen) wskazuje, że pokoleniowa nostalgia za rolą minionego doświadczenia odbiorczego stała się istotnym dobrem konsumpcyjnym. Trudno przy tym określić, na ile jest to wyraz autentycznie przeżywanych emocji, a na ile są one fabrykowane w ramach dominującego modelu marketingowego.

Druga - obok nostalgicznej afirmacji - tendencja problematyzowania przeszłości to podejście krytyczne, często polegające na odwracaniu bądź dekonstruowaniu ustalonych narracji historycznych, obecnych także w kinematografii. To wewnętrznie zróżnicowane zjawisko zaistniało nawet wcześniej niż film nostalgiczny (którego wczesnym przykładem jest trend retro-noir i filmy takie jak Żegnaj, laleczko [Farewell, My Lovely, 1975, reż. Dick Richards]). Dowodzą tego antywesterny lat sześćdziesiątych i siedemdziesiątych XX wieku, czasu kontrkultury i kontestacji. Są one zwane także westernami rewizjonistycznymi, co silnie wiąże się z prezentowanym w nich podejściem do kwestii podboju Dzikiego Zachodu. W filmach tych następuje bowiem „aksjologiczne odwrócenie - dotychczasowi antybohaterowie stają się protagonistami, których nie sposób jednoznacznie potępiać”, a żądnymi krwi „barbarzyńcami okazują się nie czerwonoskórzy, lecz biali”’, czego przykłady znajdziemy w Małym wielkim człowieku (Little Big Men, 1970, reż. Arthur Penn) bądź Niebieskim żołnierzu (Soldier Blue, 1970, reż. Ralph Nelson).

Trend ten, choć pierwotnie silnie związany z protestami antywietnamskimi, kontrkulturą i kontestacją późnych lat sześćdziesiątych XX wieku, powrócił w produkcjach XXI wieku. Twórcy współczesnych westernów spod znaku demitologizacji idą jednak nawet dalej, uwagę koncentrując już nie na samym odwracaniu biegunów dobra i zła znanych z dzieł klasycznego Hollywood, ale na analizie

5. Król lew (The Lion King, 2019, reż. Jon Favreau).

6. Konrad Klejsa, Filmowe oblicza kontestacji, Trio, Warszawa 2008, s. 145. 
owych narracji jako narzędzi perswazyjnych oraz na refleksji nad ich genezą - tym, kto je wytwarza i jakim celom mają służyć. Szczególnie wyraziste przykłady takich dzieł to Zabójstwo Jessego Jamesa przez tchórzliwego Roberta Forda (The Assasination of Jesse James by the Coward Robert Ford, 2007, reż. Andrew Dominick) oraz seriale Deadwood (2004-2006) i Hell on Wheels (2011-2016) ${ }^{7}$. Do demitologizacji znanej z kina okresu kontestacji dodano w nich bowiem elementy dekonstrukcji samej historii, a także rozważania o historii jako narracji poddanej działaniu ideologii i presji różnego rodzaju interesów, partykularnych i zbiorowych. Znamienną scenę znajdziemy w Hell on Wheels, opowiadającym o budowaniu kolei przez całą Amerykę Północną. Po napadzie Indian na białych osadników, na miejsce tragedii przybywa wraz ze świtą nie tylko zarządca kolei, Thomas Durant (Colm Meaney), ale też fotograf. Zanim jednak będzie mógł zrobić pierwsze zdjęcie, Durant garściami zbiera strzały z ziemi i wbija je w ciała ofiar. Dopiero tak przygotowana i zintensyfikowana sceneria może stać się przedmiotem zdjęć i artykułu prasowego, mającego przekonać opinię publiczną o konieczności dalszego prowadzenia polityki ekspansji. Ideologia niesienia kaganka postępu i misji cywilizacyjnej, służąca w tym wypadku interesom kolei (i majątkowym Duranta), zostaje więc fałszywie spotęgowana, a częściowo nieprawdziwa narracja uruchomiona, zapisana na kliszy i papierze, a później - wraz z narodzinami kina i westernu jako gatunku filmowego - przeniesiona na srebrne ekrany.

Współczesny rewizjonizm historyczny, najczęściej kojarzony przede wszystkim z produkcjami westernowymi, zaczyna jednak obejmować także wcześniejszy okres historii Stanów Zjednoczonych, czyli niewolnictwo. Znajduje się ono w centrum zainteresowania filmów jak najdalszych od tradycyjnego mitologizowania antebellum i starego Południa, takich jak Django (Django Unchained, 2012, reż. Quentin Tarantino) i Zniewolony (12 Years a Slave, 2013, reż. Steve McQueen), pokazujących perspektywę nie plantatorów, jak w kinie klasycznym (na przykład w the southern plantation film, jak Jezebel [1938, reż. William Wyler]), lecz niewolników.

Trzecim i ostatnim generalnym rejestrem odnoszenia się do przeszłości jest podejście relatywnie neutralne, zdominowane wielokrotnie już opisanymi ${ }^{8}$ zabiegami estetycznymi, które można określić mianem recyclingu kulturowego. Strategia ta opiera się przede wszystkim na operowaniu cytatami intertekstualnymi, pastiszem i parodią (obecnymi także w pozostałych tendencjach), włączaniu elementów z dawnych stylów we współczesną narrację. Dobrym przykładem jest

7. Jeszcze wcześniej ścieżki dla tej strategii (w tonie ironicznym) przecierał Robert Altman, kręcąc w 1976 roku film Buffalo Bill i Indianie (Buffalo Bill and the Indians, or Sitting Bull's History Lessons).

8. Por. m.in. Elizabeth Guffey, Retro. The Culture of Revival, Reaktion Books, London 2006; Jacek Ostaszewski, Historia narracji filmowej, Universitas, Kraków 2018. 
przewrotny hołd dla kina klasycznego, czyli (Hail, Caesar!, 2016, reż. Joel i Ethan Coen). Film, którego koncepcja jest wybitnie kinofilska, to mozaika niezliczonych nawiązań do kinematograficznej kultury epoki, a twórcy przywołują liczne konwencje, które definiowały okres powojenny, kiedy toczy się akcja - poczynając od film noir, peplum, film wodny, western, musical, kończąc na dramacie z wyższych sfer. Status cytatów intertekstualnych jest rozmaity, a wszystkie mieszczą się w ramach autotematyzmu pierwszego stopnia (film o filmie) ${ }^{9}$, bracia Coen przeprowadzają bowiem widza przez kilka hollywoodzkich planów zdjęciowych.

Z jednej strony w filmach tego typu akcent zostaje wyraźnie przesunięty na zabiegi estetyczno-narracyjne, stające się ich fundamentem oraz punktem wyjścia dla ich analizy oraz interpretacji, co znajdziemy w filmach postmodernistycznych spod znaku nie tylko wspomnianych już braci Coen, lecz także Briana de Palmy i Quentina Tarantino. Z drugiej - istotne jest nieustające przywoływanie i redefiniowanie ikon popkultury we współczesnym kinie typu high concept, na przykłąd superbohaterskim, opartym na niekończącym się ciągu prequeli, sequeli i rebootów.

\section{Retro - neutralne i krytyczne}

Szczególnie wyróżniającym się na tym tle podejściem do uobecniania przeszłości we współczesnym kinie amerykańskim jest krytyczne retro, należące - jak wskazuje sama nazwa - do drugiej z zarysowanych powyżej ogólnych tendencji. Samo pojęcie retro, czasem błędnie utożsamiane $\mathrm{z}$ nostalgią ${ }^{10}$, ma charakter wyłącznie estetyczny. Najtrafniej zdefiniował je Simon Reynolds, pisząc o „świadomym fetyszyzowaniu minionej epoki (poprzez muzykę, stroje oraz stylistykę wnętrz i przedmiotów), a realizowanym dzięki twórczemu wykorzystaniu pastiszu i cytatu"11, i szerzej - o luźnym określeniu wszystkich zjawisk odnoszących się do względnie nieodległej przeszłości kultury popularnej. Ujęcie to podkreśla rolę emocjonalnie neutralnego aspektu estetycznego (w opozycji do nacechowanej psychologicznie nostalgii) oraz konkretne narzędzia wiązane z postmodernizmem, wskazujące na autorefleksyjność jako element konieczny zaistnienia retro.

Wśród dalszych wyróżników warto zwrócić uwagę na zakres czasowy - retro dotyczy nowoczesności nadal istniejącej w „żywej” pamięci, a jego umowną cezurą jest początek rewolucji przemysłowej, ponieważ właśnie ten czas pokrywa się z istnieniem mediów dosłownie rejestrujących rzeczywistość. Między innymi ta cecha odróżnia retro od zawsze obecnego w kulturze sięgania do przeszłości

9. Por. Ostaszewski, Historia myśli filmowej..., s. 195.

10. Jameson, Postmodernizm..., s. 197.

11. Simon Reynolds, Retromania. Jak popkultura żywi się własna przeszłościa, przeł. Filip Łobodziński, Kosmos Kosmos, Warszawa 2018, s. 12. 
„zamkniętej”, na przykład niemijającej mody na gotycyzm i wiktorianizm. Oznacza to również, że retro opiera się na materiałach audiowizualnych (nagraniach audio i wideo, fotografiach), dzięki którym styl minionych epok można odtworzyć całkowicie dosłownie. Jest to zauważalne zwłaszcza w kinie, w którym samoświadome, pastiszowe odwołanie do konkretnej estetyki (na przykład danego gatunku filmowego bądź mody) często można określić wręcz mianem hiperstylizacji. Na koniec ogólnej charakterystyki retro warto też zauważyć, że funkcjonuje ono w obszarze kultury popularnej, jej ikon, filmów, piosenek, programów telewizyjnych, co odróżnia je od innych rodzajów sięgania do przeszłości, które "powstawały w łonie najwyższych warstw społecznych, wśród artystowskich arystokratów i antykwariuszy o wyrafinowanych upodobaniach do wykwintnych egzemplarzy kolekcjonerskich”12. Dlatego „atrybuty retro, jego autorefleksyjność, ironiczne przedstawienia przeszłości, lekceważenie dla tradycyjnych granic oddzielających »wysokie« od »niskiego« są echem kwestii fundujących teorię postmodernizmu"13.

Warto w tym miejscu zauważyć, że strategie operowania modą retro są szczególnie trafnym narzędziem analizy formowania pamięci kolektywnej przez wytwory kultury. Pamięć taką rozumiem, za Astrid Erll, jako ukształtowaną społecznie i kulturowo, „pamiętającą [...] dzięki specyficznym dla danej kultury schematom, działającą zgodnie z kolektywnie podzielanymi normami i wartościami oraz asymilującą doświadczenia czerpane z drugiej ręki do własnego zasobu doświadczeń"14. Pamięć taka jest zmediatyzowana - nie może istnieć bez mediów, a zatem podlega mechanizmom wynikającym $z$ ich natury. W wypadku produkcji filmowo-serialowych, które można zaliczyć do kategorii „tekstów zbiorowych”, rozpatrywanych nie ze względu na ich indywidualne cechy i w kategoriach artystycznych, ale jako nośniki „zbiorowych tożsamości, obrazów historii, wartości i norm"15, będą to - między innymi - wpisywanie w określone konwencje oraz narratywizacja. Ponadto „pamięć kulturowa jest zorientowana na utrwalone punkty w przeszłości. Także ona nie potrafi przechować pamięci jako takiej. Przemienia ją więc w symboliczne figury, na których się wspiera”"16. Pozwala to twórcom kina operować „wrażliwością

12. Reynolds, Retromania..., s. 36.

13. Guffey, Retro. The Culture of Revival..., s. 14.

14. Astrid Erll, Literatura jako medium pamięci zbiorowej, przeł. Magdalena Saryusz-Wolska, w: Pamięć zbiorowa i kulturowa. Współczesna perspektywa niemiecka, red. Magdalena Saryusz-Wolska, Kraków 2009.

15. Erll, Literatura jako medium pamięci zbiorowej..., s. 233.

16. Jan Assmann, Pamięć kulturowa. Pismo, zapamiętywanie i polityczna tożsamość w cywilizacjach starożytnych, przeł. Anna Kryczyńska-Pham, Wydawnictwa Uniwersytetu Warszawskiego, Warszawa 2008, s. 68. 
proustowską" związaną z wywoławczą (cue) funkcją mediów (w relacji z pamięcią), czyli uruchamianiem procesów pamięci przez „obrazy, teksty, fragmenty dialogów"17, które wcześniej, na zasadzie sprzężenia zwrotnego, przyczyniły się do jej kształtowania.

Owe obrazy, punkty krystalizacji pamięci, istnieją w artefaktach i mediach, reprodukowane - na przykład - w dziełach dostarczających kontekstu (budowanego fabularnie, gatunkowo, narracyjnie i stylistycznie), od którego zależy, na jakim biegunie ideologicznym będzie lokowała się dana wizja przeszłości. O ile w filmach nostalgicznych późnych lat siedemdziesiątych i osiemdziesiątych XX wieku była ona idealizowana, co widać w produkcjach opisanych przez Jamesona, o tyle w krytycznym retro optyka twórców diametralnie się odwraca.

Krytyczne retro, będące jednym z prężniejszych nurtów amerykańskiego kina XXI wieku, cechuje się oczywiście wszystkimi elementami charakteryzującymi samo retro, ale oznacza też coś więcej niż tylko komponent polemiczny zawarty w nazwie. Co interesujące, obrazuje ten sam okres, co filmy nostalgiczne, czyli lata pięćdziesiąte - szczególnie mitologizowaną $\mathrm{w}$ amerykańskiej popkulturze erę Eisenhowera ${ }^{18}$ (spełniony zostaje więc warunek dotyczący przeszłości istniejącej w żywej pamięci). Stanowczo odżegnuje się jednak od nich jako „uprzywilejowanego, straconego obiektu pożądania [...] stabilizacji i pomyślności pax Americana"19. Choć krytyczne ujęcie relatywnie nieodległej przeszłości jest w omawianym nurcie najważniejsze i stanowi podstawowy wyróżnik tożsamościowy, krytyczne retro cechuje się także kilkoma dodatkowymi, specyficznymi dlań strategiami i nie jest po prostu kolejną odsłoną rewizjonizmu.

Radykalna demitologizacja ery Eisenhowera odbywa się tu na kilka sposobów, z których najbardziej oczywistym i eksponowanym są zabiegi wizualne (i audialne) składające się na hiperstylizację opartą na autotematyzmie. „Estetyczna kolonizacja" ${ }^{20}$ omawianego okresu obejmuje jednak nie tylko przefiltrowanie diegezy przez modę i design ery Eisenhowera, co byłoby typowe także dla filmów

17. Erll, Literatura jako medium pamięci zbiorowej..., s. 221.

18. W Stanach Zjednoczonych przyjęło się rozumieć lata pięćdziesiąte jako okres szerszy niż tylko przedział 1950-1959. Jest on umowny i symboliczny, obejmujący powojenną prosperity zaczynającą się już w 1945 roku i rozciągającą do 1963 roku, czyli zamachu na Johna Kennedy'ego (Por. Guffey, Retro..., s. 100). Równie elastyczne jest określenie era Eisenhowera (którego dwie kadencje przypadły na lata 1953-1961), obejmujące prezydenturę Harry’ego Trumana (1945-1953), i Kennedy'ego (1961-1963). Oba terminy będę stosować w szerokim znaczeniu, dlatego za przykłady posłużą mi także produkcje, których akcja jest osadzona na początku lat sześćdziesiątych (ale nie później niż w 1963 roku). Wśród nielicznych na razie przykładów aplikowania krytycznego retro do innych epok można wymienić Czarne bractwo. BlacKkKlansman (BlacKkKlansman, 2018, reż. Spike Lee), osadzone w latach siedemdziesiątych XX wieku.

19. Jameson, Postmodernizm..., s. 75.

20. Jameson, Postmodernizm..., s. 76. 
"po prostu” historycznych, ale też przez jej popkulturę i media. Nie ogranicza się też wyłącznie do żonglowania cytatami (charakterystycznego dla recyclingu kulturowego), ale wkracza w obszary wieloaspektowego problematyzowania. W tym wypadku autotematyzm jako narzędzie interpretacyjne oznacza bowiem staranne konstruowanie świata przedstawionego na podstawie zarówno jego cech stylistycznych, składających się na idealną fasadę - podstawę mitologizacji w kinie nostalgicznym i dekonstrukcji w krytycznym retro - jak i konwencji filmowych oraz narracji charakterystycznych dla ery Eisenhowera. Innymi słowy, kreacja i krytyka świata lat pięćdziesiątych zostają umieszczone w ramach jego popkultury, a współczesne produkcje w niej osadzone przywołują formuły takie, jak melodramat rodzinny (Daleko od nieba [Far From Heaven, 2002, reż. Todd Haynes]), film korporacyjny (Mad Men; AMC 2007-2015) ${ }^{21}$, a nawet sandałowy ${ }^{22}$ (do pewnego stopnia w Ave, Cezar!).

Ambicje twórców krytycznego retro idą jednak jeszcze dalej i nie ograniczają się do przywołania konkretnych, niekiedy dawno już zarzuconych wytworów Hollywood lat pięćdziesiątych. Kolejną cechą charakterystyczną nurtu jest bowiem to, że owe oswojone formuły wykorzystywane są do celów subwersywnych, przede wszystkim wypełniania luk pojawiających się w klasycznych konwencjach, konsekwencji nakazów kodeksu Haysa ${ }^{23}$ i atmosfery społecznej represjonującej pewne tematy. Chodzi tu przede wszystkim o wprowadzanie do współczesnych produkcji doświadczeń grup marginalizowanych w narracjach wcześniejszych, nieobecnych lub podporządkowanych jednolitej perspektywie większościowej, takich jak Afroamerykanie, mniejszości seksualne bądź kobiety. Warto pamiętać, że do 1956 roku kodeks zakazywał, między innymi, pokazywania związków międzyrasowych.

Autotematyzm, w tym wypadku polegający głównie na wprowadzaniu do filmów elementów medialnego zapośredniczenia diegezy przez popkulturę z epoki, pozwala wskazać źródła owych luk (wypełnianych przez krytyczne retro). Podkreśla zarazem dyskursywność ekranowych reprezentacji, zrywając z nadrzędną zasadą klasycznego modelu kina, budującego wrażenie naturalności i neutralności fabuły poprzez przezroczystość narracji i środków filmowych. „Naczelny chwyt [...] kina klasycznego to "przebranie dyskursu za fabułę«; zmierza ono poprzez

21. Mad Men to oczywiście serial, jednak jego twórcy odwołują się do konwencji filmów korporacyjnych lat pięćdziesiątych, takich jak Rada nadzorcza (The Executive Suit, 1954, reż. Robert Wise), Człowiek w szarym, flanelowym garniturze (Man in the Gray Flannel Suit, 1956, reż. Nunnally Johnson) bądź Patterns (1956, reż. Fielder Cook).

22. Filmami sandałowymi (bądź filmami miecza i sandała) określa się epickie antyczno-biblijne produkcje z lat pięćdziesiątych i sześćdziesiątych. Nazwa wzięła się od obowiązkowego w nich elementu kostiumu.

23. Wewnętrzna cenzura hollywoodzka obowiązująca w latach 1934-1968. 
"przezroczystość narracji« do wywołania wrażenia, że »fabuła opowiada się sama«"24. Krytyczne retro przypomina zaś o uwikłaniu każdej realizacji filmowej i telewizyjnej w sieć okoliczności - ekonomicznych, politycznych, społecznych wpływających na kształtowanie wizerunku epoki, a zarazem przestrzeń pamięci zbiorowej.

Krytyczne retro można więc, w sensie całkiem dosłownym, określić mianem poetyki pamięci - zespołu określonych środków formalnych charakterystycznych dla nurtu, których zadaniem jest kształtowanie pamięci kolektywnej o konkretnych epokach. Określone wykorzystanie filmowych środków wyrazu (stylizacja), zabiegów narracyjnych oraz autotematyzmu, zgodnie z wyraźnymi intencjami twórców, mają przełożyć się na krytyczną refleksję - na razie przede wszystkim o erze Eisenhowera, zarówno jako o rzeczywistym okresie w historii XX-wiecznych Stanów Zjednoczonych, jak i o mitologizowanym czasie amerykańskiej sielanki.

\section{Hiperstylizacja}

W odniesieniu do krytycznego retro pojęcie stylizacji nie oznacza wyłącznie - oczywistej w wypadku każdego filmu rozgrywającego się w przeszłości - staranności przygotowania kostiumów, dekoracji i rekwizytów. Mise-en-scène nie jest tu wartością autoteliczną, choć oczywiście zadaniem inscenizacji także w tym wypadku jest osadzenie akcji we właściwym momencie czasowym. W krytycznym retro odbywa się to jednak nie tyle przez stworzenie prawdopodobnego tła zdarzeń, ile przywołanie i zintensyfikowanie natychmiast rozpoznawalnych orientacyjnych punktów pamięci. W odniesieniu do ery Eisenhowera funkcję taką mogą pełnić, na przykład, ikoniczne dla epoki aseptyczne przedmieścia oraz typowe postaci uosabiające oczekiwane i społecznie sankcjonowane role (sfrustrowanej) pani domu ubranej w stylu New Look bądź mężczyzny w szarym, flanelowym garniturze.

Twórcy spod znaku krytycznego retro omalże ścigają się na szczególnie efektowne sposoby wykorzystania stylu epoki. Wiele najtrafniejszych przykładów samoświadomej strategii wizualnej znajdziemy w Daleko od nieba oraz w Mad Men, serialu, którego nie tylko zamysł, ale także kampania reklamowa w dużej mierze opierały się na podkreślaniu roli stylizacji i nawiązań do popkultury epoki. W pierwszych trzech sezonach Mad Men (ich akcja rozgrywa się przed 1963 rokiem i zamachem na prezydenta Kennedy'ego) jedna z wiodących bohaterek, Betty Draper (January Jones), jest konsekwentnie stylizowana na Grace Kelly. Ma to znaczenie nie tylko dlatego, że gwiazda była ikoną i ucieleśnieniem stylu

24. Tadeusz Lubelski, Strategie autorskie w polskim filmie fabularnym lat 1945-1961, Rabid, Kraków 2000, s. 55. 
New Look oraz wzorem dla milionów Amerykanek, ale także na metapoziomie. Ponieważ Betty jest w krytycznym retro jednym $\mathrm{z}$ najdonioślejszych przykładów kobiety udomowionej, cierpiącej na problem bez nazwy ${ }^{25}$, nieprzypadkowe jest przywołanie jej akurat przez postać Kelly, kobiety porzucającej błyskotliwą karierę zawodową, by stać się księżną Monako (czyli dla małżeństwa, które później uniemożliwiło jej powrót do pracy ${ }^{26}$. Wybory życiowe Grace Kelly wpisywały się w wymogi społeczne lat pięćdziesiątych, kluczowe także dla interpretacji postaci Betty. Dodatkowo osadza to bohaterkę, ucieleśnienie ideału epoki - kobiecości przedmieść, domowej i rodzinnej, ale będącej przy tym efektownym, ozdobnym akcesorium u boku pracującego w metropolii męża - we właściwym kontekście.

Już ten jeden reprezentatywny przykład z Mad Men pokazuje, że stylizacja w krytycznym retro jest nie tylko fetyszystycznie staranna i autorefleksyjna, ale też jej samoświadomość ma podstawowy wpływ na konstrukcję i odczytanie analizowanych tekstów. Podobnie jest w Daleko od nieba, gdzie - poczynając od pierwszych ujęć - Todd Haynes nawiązuje nie tylko do określonej i typowej dla epoki konwencji ( $g$ lamour melodrama), lecz także do konkretnego i słynnego filmu, czyli Wszystko, na co niebo zezwala (All that Heaven Allows, 1955, reż. Douglas Sirk). Nawet jednak pamięć widzów, którzy nie rozpoznają charakterystycznej czołówki imitującej otwarcie filmu Sirka, powinna zostać pobudzona i prawidłowo zorientowana przez elementy takie jak liternictwo, muzyka, zdjęcia i kolorystyka nawiązująca do technikoloru (systemu utożsamianego z kinem lat pięćdziesiątych), a także przez detale mise-en-scène ukazywane łagodnym travellingiem - postaci kobiece ubrane w stylu New Look, wielkie auta i przedmieścia. W ten sposób już czołówka filmu wprowadza wyraziste drogowskazy dla określonych skojarzeń, obecne także w całym filmie Haynesa i innych produkcjach krytycznego retro. Elementy te oddziałują przez intensyfikację, w pewien sposób są tautologiczne, ale gdyby zatrzymać kolejne kadry, wyizolować czcionkę, kolory, tło - każdy z nich z osobna ma potencjał pobudzania pamięci w sposób, który jest całkowicie obcy filmom dalekim od samoświadomości, o „przezroczystej” stylistyce (dla porównania - również osadzony w latach pięćdziesiątych Most szpiegów [Bridge of Spies, 2015, reż. Steven Spielberg]).

Twórcy stosujący autotematyczne nawiązania stylistyczne nie poprzestają jednak na zasygnalizowaniu czasów i tworzeniu związków znaczeniowych (na przykład

25. „Problem bez nazwy” to opisana w Mistyce kobiecości przez Betty Friedan przypadłość pań domów z przedmieść w erze Eisenhowera, które oddając się tylko oczekiwanym przez ogół zajęciom domowym i rodzinnym, nie odczuwały życiowej satysfakcji. Miały wszystko, co - zgodnie z obowiązującą ideologią - powinno przynieść im szczęście, ale go nie odczuwały, nie potrafiąc jednocześnie wskazać źródła frustracji (stąd określenie „bez nazwy”). Betty Friedan, Mistyka kobiecości, przeł. Agnieszka Grzybek, Wydawnictwo Czarna Owca, Warszawa 2010, s. 60.

26. Grace Kelly planowała powrót na wielkie ekrany, ale nie pozwolił jej na to protokół pałacowy. 
przez zrównanie przedmieść i stylu New Look z opresją sztywnej roli społecznej). Hiperstylizacja służy też budowaniu perfekcyjnej fasady, niezbędnego punktu wyjścia dla dekonstrukcji mitologizowanego obrazu ery Eisenhowera. Oczywiście demitologizacja odbywa się za pomocą wszystkich strategii - fabularnej, rysunku postaci, krytycznego spojrzenia na przeszłość - ale także w wizualnej konstrukcji świata przedstawionego. Im większa i bardziej ostentacyjna jest perfekcja stylizacji, tym większy ładunek ironiczny, który ze sobą niesie, nieufność widzów ${ }^{27}$ i dobitniejsze podważanie ich przekonania o naturalności i neutralności ekranowych przedstawień. Stylizacja wzniesiona na poziom „hiper”, obok przywoływania czasu akcji, powinna stać się więc środkiem dystansującym, a przez to demaskować ideologię świata przedmieść, podając $\mathrm{w}$ wątpliwość jego wiarygodność jako „najszczęśliwszej epoki w historii Stanów Zjednoczonych - when things were going on - za którą jeszcze wszyscy tęsknią"28.

Demaskowanie fasady jest więc istotną strategią autorską twórców krytycznego retro, która często staje się także elementem wewnątrztekstowym, czyli częścią fabuły, zwłaszcza wątków związanych z postaciami kobiecymi odgrywającymi, zgodnie z wymogami czasów, role idealnych pań domu i akcesoriów u boku mężów. Nie jest przypadkiem, że wiele z nich - bohaterki Daleko od nieba (Julianne Moore), Mad Men (January Jones), Drogi do szczęścia (Revolutionary Road, 2009, reż. Sam Mendes; Kate Winslet) - przed wyjściem za mąż pracowało jako modelki i aktorki, co dostarcza czytelnych metafor kobiecości wymyślonej i wytworzonej na użytek innych, a wręcz, by użyć pojęcia stosowanego przez Mary Ann Doane - maskaradowej ${ }^{29}$. W tym sensie kobiecość takich postaci jest maską, którą można zdjąć bądź założyć, okazuje się spektaklem równie starannym i dyskursywnym, jak mise-en-scène w filmach krytycznego retro. W fabułę zostaje wplecione także zapośredniczenie medialne, widoczne już w stylizacji i doborze aktorek (na przykład January Jones - Grace Kelly, Julianne Moore - Jane $W_{y m a n}{ }^{30}$ ). Ponieważ bohaterki są zawsze wystawione na ogląd (nawet po domu chodzą na obcasach i w gorsetach), regułą krytycznego retro skoncentrowanego na białych paniach domu są sceny publicznego prezentowania ich przyciętej do szablonu epoki kobiecości. Do szczególnie znamiennych scen należą sesja fotograficzna dla lokalnej gazety dokumentującej życie „idealnej” rodziny z przedmieścia w Daleko od nieba i reklama coca-coli w Mad Men, stylizowana na piknik równie doskonałej rodziny.

27. Mam na myśli odczytanie widza zakładanego - wpisanego w tekst.

28. Jean Baudrillard, Ameryka, przeł. Renata Lis, Sic!. Warszawa 1998, s. 144.

29. Zob. Mary Ann Doane, Film and the Masquerade: Theorising the Female Spectator, „Screen” 1982, nr 3-4 (23).

30. Jane Wyman grała główną rolę we Wszystko, na co niebo pozwala, czyli filmie, do którego odwołuje się Daleko od nieba. 
Obraz ten jest jednak ironicznie kontrapunktowany sztuczną dekoracją i tłem planu zdjęciowego.

Szczególny wydźwięk zabieg ten znajduje w Jackie (2016, reż. Pablo Larraín), filmie podporządkowanym rozważaniom na temat roli kobiety, której egzystencja ograniczona jest do funkcji żony (w tym wypadku pierwszej damy - Jacqueline Kennedy zagranej przez Natalie Portman). Rola ta jest odgrywana nawet mniej w sferze domowej, a bardziej - i całkiem literalnie - na oczach świata. Także tutaj środki filmowe wzmacniają wydźwięk zabiegów dosłowniejszych, takich jak werbalizacja podstawowych dla filmu kwestii (pytania o tożsamość bohaterki w momencie utraty i męża, i funkcji pierwszej damy) oraz stawianie Jackie w określonych sytuacjach. Są wśród nich inscenizacja słynnego programu dokumentalnego A Tour of the White House (1962, reż. Franklin J. Schaffner) ${ }^{31}$, przeżywanie żałoby po zamachu w prywatnych pokojach Białego Domu, ale na oczach agentów Secret Service, wystawianie się na widok publiczny w jeszcze zakrwawionej garsonce $^{32}$, przemarsz w kondukcie pogrzebowym. Za przykład rozwiązań czysto wizualnych mogą posłużyć ujęcia Natalie Portman odbijającej się w wielu lustrach jednocześnie bądź rola kostiumów - Kennedy, podobnie jak Grace Kelly, była ikoną stylu swej epoki.

\section{Narracja}

Stylizacja sama w sobie, choć pełni kluczową rolę w krytycznym retro, tylko częściowo przekłada się na jego główne dążenie (będące zarazem strategią), czyli wypełnianie luk w oswojonych narracjach, a zarazem zapisywanie białych plam w historii. Ten cel najłatwiej osiągnąć fabularnie, stąd obecność postaci takich jak panie domu, których frustracja wynika z opresyjności oczekiwań społecznych i kruchości fasady świata przedstawionego. Twórcy krytycznego retro sięgają jednak także po rozwiązania narracyjne, czyniąc fokalizatorami ${ }^{33}$ postaci tradycyjnie wykluczane ze sprawstwa bądź przydzielając im narrację pierwszoosobową prowadzoną w voice over (czyli homodiegetyczną), a tym samym uprzywilejowując ich punkt widzenia. Tak dzieje się w trzech kluczowych dla nurtu filmach poruszających problematykę rasizmu, czyli w Stużących (The Help, 2012, reż. Tate Taylor), Kamerdynerze (The Butler, 2013, reż. Lee Daniels) i Ukrytych działaniach

31. Po raz pierwszy w historii ekipa telewizyjna została zaproszona do Białego Domu, dokumentując Jackie Kennedy oprowadzającą dziennikarza po rezydencji i opowiadającą o jego historii. A Tour of the White House przyniosło Jackie Kennedy nagrodę Emmy.

32. Jacqueline Kennedy odmówiła przebrania się przed przybyciem z ciałem prezydenta do Waszyngtonu.

33. Fokalizator (postać ogniskująca) to bohater, który zapośrednicza punkt widzenia odbiorców. 
(Hidden Figures, 2016, reż. Theodore Melfi). Już zastosowane w każdym z nich przesunięcie postaci Afroamerykanów na plan pierwszy, a białych na drugi i trzeci, wskazywałoby intencje twórców, którzy jednak na tym nie poprzestają i wykorzystują możliwości narracyjne. Najdalej pod względem subiektywizacji idą autorzy rozgrywających się w 1963 roku w Mississippi Służących, gdzie już w ekspozycji podkreślony zostaje zamiar zmiany perspektywy i stworzenia kontrnarracji wobec dominującego w kinie punktu widzenia białych bohaterów. To, że głos i perspektywa Afroamerykanek jest dominującym tematem filmu, przeważającym nad perypetiami białych bohaterek, wynika oczywiście z samej fabuły koncentrującej się na wysiłkach Skeeter (Emma Stone), aspirującej dziennikarki, by namówić służące z Jacksonville do zwierzeń na temat własnego życia i często traumatycznych relacji z białymi paniami. Czarne bohaterki obawiają się konsekwencji opublikowania swoich historii, a ich sytuacja uzasadnia te lęki - żyjąc pod prawami Jima Crowa, są de facto współczesnymi niewolnicami.

Tematyzowanie znaczenia własnego głosu i punktu widzenia przejawia się jednak także w ustawieniu narracji spójnej z fabułą - już w drugim ujęciu Viola Davis, grająca główną rolę Aibileen, patrzy prosto w kamerę i opowiada o determinującym jej możliwości życiowe pochodzeniu z rodziny służących i niewolnic. Kompozycja kadru (przełamanie czwartej ściany, czyli podstawowej zasady przezroczystości środków filmowych) sprawia, że adresatami tych słów - w stopniu większym niż Skeeter, druga postać ze sceny otwierającej - są widzowie zachęcani do skupienia uwagi na losach z reguły pomijanych w kinie. Czarne służące, często obecne zwłaszcza w filmach złotej ery Hollywood ${ }^{34}$, z zasady były bowiem anonimowe i pozbawione własnego życia poza pracą dla białych, zawsze wpisywane w stereotyp Mammy, czyli czarnej niani. Intencja oddania głosu czarnym kobietom, pozbawionym go zarówno w takich produkcjach, jak i społeczeństwie, w ekspozycji Służących zostaje wzmocniona, gdy na pierwsze kwestie Aibileen wypowiedziane do Skeeter (dźwięk diegetyczny) nakłada się voice over (dźwięk niediegetyczny, słyszany już tylko przez widzów). Na obu poziomach (dźwięku diegetycznego i niediegetycznego) Aibileen opowiada o doświadczeniu swoim i wielu kobiet takich jak ona, służących i nianiek w domach białej klasy średniej („wychowałam siedemnaścioro białych dzieci”). Jak się okazuje w kolejnych scenach, film ma kompozycję klamrową i pierwsze ujęcia są wstępem do retrospekcji, co po raz trzeci w pierwszych dwóch minutach filmu podkreśla, że punkt widzenia należy do Aibileen ${ }^{35}$.

34. Okres od lat trzydziestych do końca pięćdziesiątych.

35. Mimo wyraźnie zaznaczonych w pierwszych ujęciach intencji twórców, narracja Stużących jest niekonsekwentna (co może wynikać zarówno z konwencjonalnych przyzwyczajeń, jak i tego, że reżyser był debiutantem); niekiedy wysuwa na plan pierwszy białą Skeeter i zaburza tym samym 
Także w Kamerdynerze narracja prowadzona z offu zyskuje znaczenie głębsze niż tylko konwencjonalnego środka typowego dla formuły kina biograficznego. Film opowiada historię życia Cecila Gainesa (Forrest Whitaker), wzorowanego na Eugenie Allenie, prawdziwym czarnoskórym kamerdynerze przez wiele dekad pracującym w Białym Domu. Akcja rozpoczyna się w dzieciństwie bohatera spędzonym w latach trzydziestych XX wieku na plantacji bawełny na Południu, a kończy się współcześnie, pierwszą kadencją Baracka Obamy. Wprowadzenie konwencji retrospekcji wydaje się więc zabiegiem ogranym, przyglądając się jej przez pryzmat krytycznego retro można jednak zauważyć, że spełnia ona dodatkowe funkcje związane ze strategią wypełniania luk w oswojonych narracjach. Przede wszystkim, podobnie jak w Stużących, pozwala na zmianę tradycyjnej hollywoodzkiej - białej - perspektywy, wysunięcie Afroamerykanów na pierwszy plan oraz przedstawienie wydarzeń z ich punktu widzenia. Zyskuje to szczególne znaczenie, ponieważ film jest swego rodzaju antologią poszczególnych etapów walki o prawa obywatelskie, które Cecil obserwuje przez pryzmat pracy w Białym Domu. Z jednej strony styka się z kolejnymi prezydentami odpowiedzialnymi za konkretne rozwiązania i legislację (sprawa liceum w Little Rock w kadencji Eisenhowera, Civil Rights Act z 1964 roku za rządów Lyndona B. Johnsona), z drugiej, jego syn (David Oyelowo) jest aktywnym działaczem ruchu, biorącym udział, między innymi, w akcjach Freedom Riders i rejestrowaniu czarnych wyborców na Południu. To także pozwala na przywrócenie sprawczości Afroamerykanom, ponieważ kolejną tradycją kina głównego nurtu było przypisywanie pierwszoplanowej roli w walce o równouprawnienie postaciom białym, co widać w wielu filmach z cyklu kina walki o prawa człowieka ${ }^{36}$, na przykład w Mississippi w ogniu (Mississippi Burning, 1988, reż. Alan Parker) bądź Czasie zabijania (A Time to Kill, 1996, reż. Joel Schumacher).

Przy okazji omawiania związków zabiegów narracyjnych z wypełnianiem luk w historii, warto wspomnieć jeszcze o Ukrytych działaniach. Wprawdzie twórcy nie uciekają się tu do tak dosłownych zabiegów, jak voice over, ale także uprzywilejowują perspektywę bohaterek, czarnych matematyczek i fizyczek pracujących przy programie Mercury w NASA. Zastosowanie rozbitej na trzy główne postacie narracji pozornie zależnej ${ }^{37}$ pozwala całkowicie zapośredniczyć spojrzenie widzów i ograniczyć postrzeganie sytuacji (związanych przede wszystkim z dyskryminacją rasową i płciową) do punktu widzenia bohaterek.

jednoznaczność kwestii sprawstwa. Z tego powodu Stużące, pomijając scenę otwierającą, są bardziej problematycznym (i często krytykowanym) przykładem niż Kamerdyner i Ukryte działania.

36. Por. Sharon Monteith, The Movie-made Movement: Civil Rites of Passage, w: Memory and Popular Film, red. Paul Grainge, Manchester University Press, Manchester-New York.

37. Postać ( $w$ tym wypadku trzy postacie znajdujące się w podobnej sytuacji i podzielające punkt widzenia) jest obecna w każdej scenie z filmu. 
W Ukrytych działaniach podkreśla się jednak nie tylko ich mierzenie się z wrogą rzeczywistością uprzedzeń i ograniczeń, lecz także sprawstwo w programie kosmicznym - film (a wcześniej książka) naprawdę wypełnia białe karty historii, wydobywając bohaterki z niewiedzy i wprowadzając je do pamięci kolektywnej - przez wpisanie w popkulturę.

\section{Autotematyzm}

Autotematyzm w kinie może oznaczać wiele różnych rzeczy - poczynając od najprostszej kwestii, czyli filmu rozgrywającego się na planie filmowym, aż po problematyzowanie aktu patrzenia, bowiem „artystyczna refleksywność odnosi się do procesu, w którym teksty wysuwają na plan pierwszy swoje własne powstawanie, autorstwo, intertekstualne wpływy, procesy tekstualne oraz percepcję" ${ }^{38}$. Również w krytycznym retro przejawy autotematyzmu są rozmaite - sam tylko Ave, Cezar! braci Coen dostarcza bogatego katalogu tego typu zabiegów, otwierając zróżnicowane metapoziomy (na przykład konwencja filmu o realizacji filmu, cytaty z klasyków kina, refleksja o istocie i funkcjach kinematografii). Najwięcej możliwości osiągnięcia celu wypełniania luk i wpływania na pamięć zbiorową daje jednak strategia przywoływania konkretnych dzieł filmowych z problematyzowanej epoki, czyli w tym wypadku ery Eisenhowera. Tak kilkukrotnie dzieje się w Mad Men, na przykład gdy pojawiają się odniesienia do Wszystko, co najlepsze (The Best of Everything, 1959, reż. Jean Negulesco) - w pierwszym sezonie bohaterowie idą do kina i czytają pierwowzór literacki, w późniejszych biuro agencji reklamowej, gdzie toczy się akcja, jest wzorowane na wystroju wydawnictwa z dzieła Negulesco. Wybór Wszystkiego, co najlepsze nie był przypadkowy, jest to bowiem rzadki przykład produkcji z ery Eisenhowera pokazującej pracę kobiet. Zgodnie z ideologią czasów, jego twórcy dowodzą jednak, że jedynym przeznaczaniem i drogą do szczęścia dla kobiet są dom i rodzina. Mad Men, przywołując ten film jako punkt wyjścia, także tematyzuje kwestię obecności kobiet na rynku pracy, demaskuje jednak konserwatywną ideologię przez odwrócenie perspektywy i pokazanie prawdziwego problemu, jakim w istocie jest dyskryminacja, a nie ambicja wykraczająca poza narzucaną społecznie rolę płciową.

Najsłynniejszym przykładem takiego autotematyzmu jest jeden z filmów założycielskich krytycznego retro, czyli wspominane już Daleko od nieba. Todd Haynes, zarówno wizualnie, jak i fabularnie, podąża śladami Douglasa Sirka, dokonując swoistego remake'u Wszystko, na co niebo zezwala. Melodramat Sirka opowiada historię Cary (Jane Wyman), wdowy z bogatych przedmieść wdającej

38. Alicja Helman, Andrzej Pitrus, Podstawy wiedzy o filmie, Słowo/obraz terytoria, Gdańsk 2008, s. 222. 
się w romans z młodszym mężczyzną z nieco niższej klasy społecznej, czyli zatrudnianym przez siebie ogrodnikiem (Rock Hudson). Tematem filmu jest więc zakazana miłość spotykająca się z ostracyzmem ze strony dorosłych już dzieci Cary oraz społeczności, do której bohaterka przynależy. W połowie lat pięćdziesiątych Sirk mógł zasygnalizować opresyjność ideologii wobec kobiet, do tego stopnia oddelegowanych do życia rodzinno-domowego, że omalże przestających egzystować po jego zakończeniu (wdowieństwo i dorosłość dzieci). Todd Haynes, sięgając po analogiczną fabułę w XXI wieku, może pozwolić sobie na więcej, czyli poszerzyć i wypełnić Sirkowską narrację. Dlatego w Daleko od nieba Cathy (Julianne Moore) także nawiązuje przyjaźń z ogrodnikiem, jest on jednak czarny, co pozwala reżyserowi na poruszanie kwestii relacji międzyrasowych i segregacji świata. Choć tematyka dyskryminacji trafiała na ekrany kin także w erze Eisenhowera, to jedynie w pojedynczych filmach o charakterze społecznym - w kinie gatunkowym rasizm $\mathrm{z}$ reguły był obecny (na przykład przez reprodukowanie stereotypów), ale sporadycznie tematyzowany.

Haynes poszedł w Daleko od nieba jeszcze dalej, wprowadzając także wątek nienormatywnej seksualności - małżeństwo Cathy rozpada się, ponieważ jej mąż jest gejem. Temat homoseksualizmu był w kinie jeszcze bardziej tabuizowany niż kwestie związane z rasą i do filmów, zwłaszcza głównego nurtu, trafił znacznie później niż dyskryminacja rasowa (zresztą także za sprawą Haynesa i zjawiska New Queer Cinema z przełomu lat osiemdziesiątych i dziewięćdziesiątych). Oczywiście reżyser mógł nakręcić osadzoną w latach pięćdziesiątych historię poruszającą trzy rodzaje wykluczenia - ze względu na rasę, orientację i płeć - nie przywołując kina z epoki i poprzestając na stylizacji. To jednak właśnie autotematyzm pozwala mu zwrócić uwagę nie tylko na kwestie społeczne, ale też sprawę narratywizacji rzeczywistości i narzędzia kształtowania pamięci zbiorowej - na to, co było wówczas rugowane z ekranów za pomocą kodeksu Haysa bądź podporządkowane konserwatywnej ideologii (związana z popularnością psychoanalizy tendencja do prywatyzowania problemów o genezie społecznej). Efektem jest partycypacja Haynesa i innych twórców krytycznego retro $\mathrm{w}$ reorganizowaniu pamięci zbiorowej oraz $\mathrm{w}$ przywracaniu jej pewnych kwestii, na przykład wiedzy o kryminalizacji homoseksualizmu (mąż Cathy zostaje aresztowany na początku filmu).

Krytyczne retro jest nie tylko narzędziem interpretacyjnym, przykładanym zarówno do pojedynczych produkcji, jak i nurtów filmowych, ale także strategią badawczą w namyśle nad historią kina odchodzącą od tradycyjnych wyznaczników tego typu refleksji. W tej optyce filmy odwołujące się do przeszłości wykraczają 
poza przynależność do gatunku kina historycznego oraz aparaturę studiów genologicznych (co byłoby zgodne z podejściem dominującym, z reguły analizującym historyczną adekwatność bądź strategie narratywizacyjne). Instrument, jakim w ramach memory studies jest krytyczne retro, pozwala bowiem rozważać filmy i seriale nie tylko w optyce innej niż gatunkowa, ale także bez odniesień do faktów historii „podręcznikowej”. Główną rolę odgrywają tu natomiast relacje filmów do praktyk upamiętniania dominujących w danym momencie w społeczeństwie, sprawiających, że kino staje się jednym z narzędzi historycznej polityki pamięci.

Krytyczne retro wskazuje także, że - inaczej niż jeszcze pod koniec XX wieku sądzili liczni krytycy i teoretycy postmodernizmu - odwołania do przeszłości nie muszą automatycznie wiązać się z jej idealizowaniem. Niezależnie od tego, czy są nostalgiczne czy krytyczne, zawsze bowiem wynikają z potrzeb teraźniejszości. W latach osiemdziesiątych, czasach popularności filmów nostalgicznych, o sielankowej i bezkonfliktowej wizji ery Eisenhowera decydowało polityczne zapotrzebowanie ustanowienia konserwatywnej wizji administracji Ronalda Reagana, legitymizowanej odwołaniami do sfabrykowanego „przedpolitycznego Edenu nastolatków”39. Współcześnie, w Obamowskiej i po-Obamowskiej erze odzyskiwania głosu i dążenia do samostanowienia przez mniejszości, przedefiniowanie ery Eisenhowera, której obraz został symbolicznie uprowadzony przez jej apologetów, pozwala na próbę innego kształtowania pamięci o tamtych czasach, co następuje w procesie ich demitologizacji. Odbieranie niewinności epoce jest też równoznaczne z wyniesieniem na piedestał tych, którzy na bieżąco walczyli z jej ograniczeniami, co najlepiej widać na przykładzie filmów o ruchach obywatelskich. W ten sposób krytyczne retro, zarówno na poziomie fabularnym, jak i środków filmowego wyrazu (jako poetyka pamięci), umożliwia tworzenie "przeciwhistorii i historii nieoficjalnej” ${ }^{\text {"40 }, ~ „ m a k s y m a l i z u j a ̨ c ~ r a d y k a l n y ~ i ~ t r a n s f o r-~}$ macyjny potencjał"41 epoki, do której się odwołuje.

39. Reynolds, Retromania..., s. 368.

40. Marc Ferro, Kino i historia, przeł. Tomasz Falkowski, PWN, Warszawa 2011, s. 11.

41. Kaja Silverman, Fragments of a Fashionable Discourse, w: Studies in Entertainment. Critical Approaches to Mass Entertainment, red. Tania Modleski, Indiana University Press Bloomington \& Indianapolis, Indiana University Press 1986, s. 151. 
